\title{
Business Confidence and Inflation in RSA: Variance Decomposition and General Impulse Response Functions Analysis
}

\author{
John Khumalo \\ University of South Africa (UNISA) \\ P.O. Box 392, Pretoria, 0003 \\ khumamj@unisa.ac.za
}

\section{Doi:10.5901/mjss.2014.v5n16p128}

\section{Abstract}

The study empirically investigates how business confidence responds to inflation shocks in South Africa using the quarterly time series data spanning the period 1993Q1 - 2013Q1. The study applied the variance decomposition and the Generalized Impulse Response Functions (GIRF) analysis. The variance decomposition revealed that although inflation accounted for about 2 percent in the initial stages, it did account for about 27 percent to shocks in business confidence at later stages. The Generalized Impulse Response Functions (GIRF) also confirmed that inflation uncertainty does cause some negative shocks on how business managers/owners perceive the future of their business prospects. These results show that there is a negative relationship between business confidence and inflation in South Africa.

Keywords: Business confidence, inflation, variance decomposition, GIRF, stationarity.

\section{Introduction}

Governments in different economies strive to push for entrepreneurship in order to create employment and boost economic growth but this does not go without some glitches due to the impact of the macroeconomic variables, such as inflation on business optimism about future expectations. Pellisier (2002) defines business confidence as the degree of sentiment towards risk - taking by business for whatever reason. When confidence falls, it is an indication that business executives or business owners are uncertain about the prospects of their company's performance. In an economy we have different types of businesses, those that are net debtors and such businesses would prefer disinflation as opposes to inflation. For some entrepreneurs, taking loans to start up business, they expect prices to be falling. They would wonder if starting a business in an economy that has falling prices or increasing prices would really benefit them. South African businesses are no exception to this uncertainty. Figure 1 below shows the historical presentation of business confidence and inflation during the years 1993 to 2013 first quarter.

Figure 1: Business confidence SA

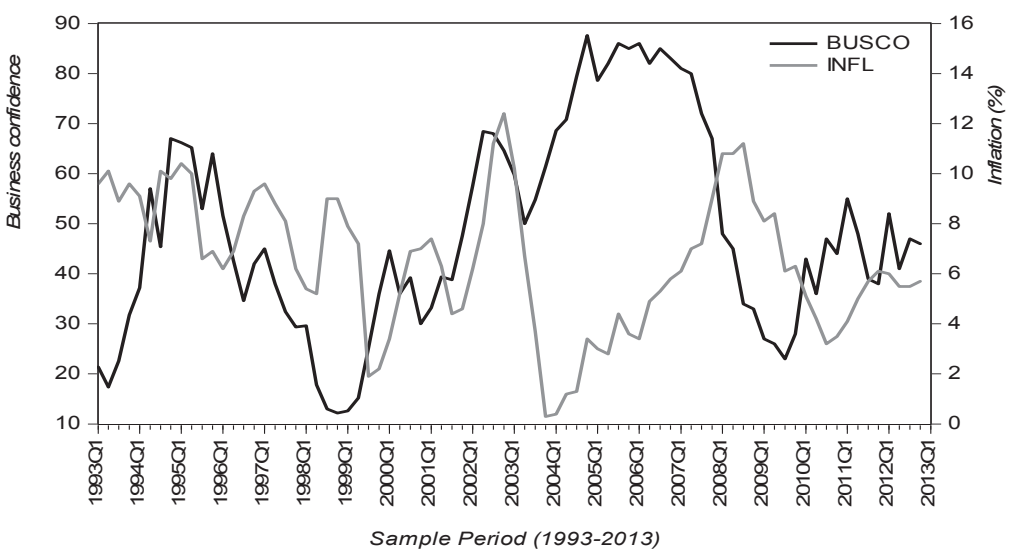


Business confidence was recorded at 21 in the first quarter of 1993 but declined in the second quarter of that same to 17. The third quarter was however characterised by an increase through 1994Q2 with an index of 57. During these periods, inflation was on the other hand seen going the opposite direction, implying that as inflation fell, business confidence increased. This is shown by the two lines on the graph. Business confidence was again seen falling 1996 through 1998Q3 after which it showed some recovery. The overall average business confidence was recorded at 45.19 for the period 1975 to 2013Q1.

Research on business sentiments has not been of that attention as compared to other literature and this was also raised by Collins (2001). Most studies seem to concentrate on consumer confidence rather than business confidence, although the two are crucial in an economy. One study by Kershoff (2000) showed that business confidence cannot only be a useful indicator of economic growth but also as a leading indicator of the business fluctuations in South Africa. Several studies have explored among others business sentiment surveys (see Friesner et al: 2006 and Hansson et al: 2005). Although such studies address business confidence, none of them explored empirically the impact of inflation uncertainty on business confidence, including but not limited to South Africa. The study by van Rooyen (2011) only attempts to give an overview of the concept and explains how business confidence is measured. According to van Rooyen (2011) indicators such as business confidence are useful for investors as such investors will only consider investing when perceptions about business conditions look favourable. This viewpoint was previously mentioned by Pellissier (2002).

As much as consumer sentiments seem to be in the forefront, some studies (Taylor and McNabb, 2007; Dennis, 2003; Nakamura and Trebing, 2008) have indicated that business surveys may contain more informative content than consumer sentiments. Friesner (2013) following this premise alluded the importance of information contained in business sentiments surveys and found that such surveys do contain a high degree of useful information. The predictive nature of business surveys sentiments help businesses plan ahead for future investments and this may lead to increased economic activity.

\section{Econometric Methodology}

The study utilises the variance decomposition and the generalised impulse response functions (GIRFs) embedded within the Vector Autoregressive methodology to detect the shocks to business confidence. The abovementioned methodology specification has been extended and modified in order to derive a model that is deemed appropriate for evaluating the impact of inflation on business confidence in South Africa. The general dynamic form of the econometric model used in this study is:

$$
B U S C_{\mathrm{t}}=\beta_{0}+\sum_{\mathrm{i}=1}^{\mathrm{k}} \beta_{1 \mathrm{i}} B U S C_{\mathrm{t}-\mathrm{i}}+\sum_{\mathrm{i}=0}^{\mathrm{k}} \beta_{\mathrm{ti}} Y_{\mathrm{t}-\mathrm{i}}+\delta_{0} D_{\mathrm{t}}+\mathbf{v}_{\mathrm{t}}
$$

where, $\mathrm{BUSC}_{\mathrm{t}}=$ business confidence, $\mathrm{Y}_{\mathrm{t}-\mathrm{i}}$ represents a set of all explanatory variables to be included in the model and their lags, $D_{t}$ represents a set of deterministic terms (dummies, trends and others). $V_{t}$ is a well behaved error term. Therefore, specifying equation (1) as a VAR system of equations gives equation (2), which is compactly written as equation (3):

$$
\begin{aligned}
& Y_{\mathrm{t}}=\boldsymbol{\delta}_{0} D_{\mathrm{t}}+\boldsymbol{\delta}_{1} Y_{\mathrm{t}-1}+\boldsymbol{\delta}_{2} Y_{\mathrm{t}-2}+\ldots \ldots \ldots \ldots \ldots+\boldsymbol{\delta}_{\mathrm{k}} Y_{\mathrm{t}-\mathrm{k}}+\boldsymbol{\pi}_{\mathrm{t}} \\
& Y_{\mathrm{t}}=\boldsymbol{\delta}_{0} D_{\mathrm{t}}+\sum_{\mathrm{i}=1}^{\mathrm{k}} \boldsymbol{\delta}_{\mathrm{i}} Y_{\mathrm{t}-\mathrm{i}}+\boldsymbol{\pi}_{\mathrm{t}}
\end{aligned}
$$

\section{Research Analysis}

\subsection{Stationarity test}

One common assumption in time series analysis is that the data are stationary. Stationarity in this case refers to a series that has a mean, variance covariance structure that do not change over time. The reliability of the results is done on both a priori criterion as well as on statistical test criterion. The results of unit root test are presented in table 1 below. 
Table 1: Unit Roots Test Results

\begin{tabular}{cccccccc}
\hline Name & DF-GLS(C) & DF-GLS(C\&T) & $M Z_{\alpha}^{G L S}$ & $M Z_{t}^{G L S}$ & $M^{G L B}$ & ${ }^{G L S}$ & Inference \\
\hline BUSCO & -1.3690 & -1.6931 & -3.5429 & -1.3080 & 0.3692 & 6.9149 & Accept null \\
GDPG & $-4.3123^{*}$ & $-4.4956^{*}$ & $-24.5403^{*}$ & $-3.5021^{*}$ & $0.1427^{*}$ & $1.0009^{*}$ & Reject null \\
INFL & -1.3315 & -1.9974 & -3.5405 & -1.2759 & 0.3603 & 6.9193 & Accept null \\
\hline
\end{tabular}

Note 1: the Ng-Perron critical values for MZa, MZt, MSB \& MP at $1 \%, 5 \%$ \& $10 \%$ are -13.8000; -8.1000; -5.7000;-2.5800, 1.1980, -1.6200 respectively. $C=$ constant, $C \& T=$ constant + trend.

Note 2: the critical values for DF-GLS at $1 \%, 5 \%$ \& $10 \%$ are $-1.25961 ;-1.9451 ;-1.6139$ respectively.

The results from the DF-Generalized Least Squares (DF-GLS) test indicate that the computed t-statistics (DFGLS statistics), in models with intercept only and those with both intercept and trend, for the two variables BUSCO and INFL are lower than the critical values at all levels of significance implying that the hypothesis of unit root cannot be rejected (See Table 1). Noting that Ng-Perron test is more powerful than the former, it implies that the results from the latter are more reliable. For $\mathrm{Ng}$ and Perron (2001) modified unit-root test of stationarity, it becomes interesting to note that two sets of statistics are positive and the other two are negative. Results from an application of $\mathrm{Ng}$-Perron test to the level form of variables show that the unit root hypothesis is accepted at all levels of significance. This is grounded on the fact that the $M Z_{\alpha}^{G L}$ and $M Z_{t}^{G L S}$ statistics are smaller than the Ng-Perron critical values. The computed ${ }^{M S B}{ }^{G L S}$ and $M P_{T}^{G L S}$ statistics also appear smaller than $\mathrm{Ng}$-Perron critical values for these statistics at all levels, thereby indicating the acceptance of the null hypothesis of unit root. Therefore, Ng-Perron test also confirms that variables are I(1).

\subsection{Granger causality analysis}

Determining the direction of causation is as much critical as other diagnostic tests used in econometric analysis because it helps to know which variable influences the other. Inflation also does not cause money growth. The hypothesis that inflation does not granger cause business confidence rejected at 5 percent level, while we accept the one for causation from BUSCO to INFL. The results are presented in table 2 below.

Table 2: VAR Granger Causality/Block Exogeneity Test results

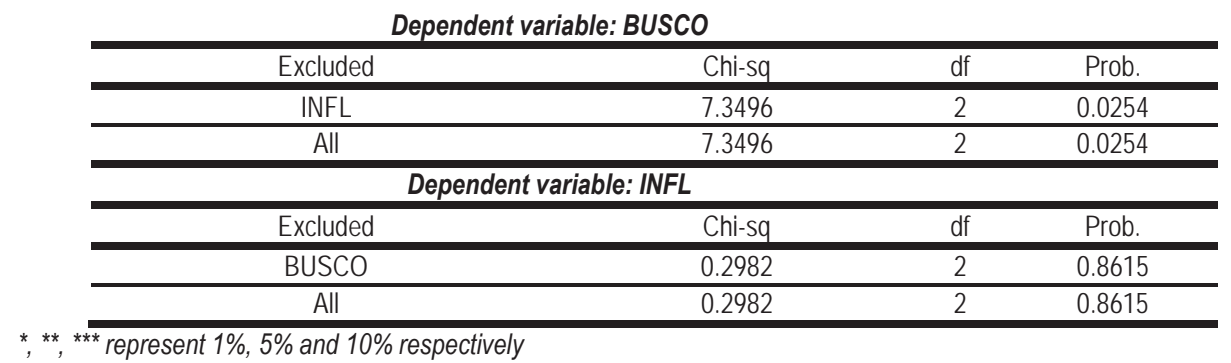

The results of exogeneity test indicate that not all variables can be treated as endogenous. The pairwise Granger causality shows that there is unidirectional causation from inflation to business confidence in the case of South Africa.

\subsection{Some diagnostic tests}

Some diagnostic tests were performed to ascertain that some tests are fulfilled and results deemed reliable. Such tests are reported in appendices $B, C$ and $D$. appendix $B$ presents the $L M$ test results on serial correlation and such results reveal no existence of serial correlation since the probability values are on average 50 percent. Most values indicate that we ought to accept the null of no serial correlation at lag order $h$. The normality test on the other hand indicates the existence of non-normality in the residuals but this may not hamper the study results that much, since the measures of skewness are found to be not informative in small samples (Bai and $\mathrm{Ng}, 2001)$. The results of the heteroskedasticity test also indicate that the null hypothesis of heteroskedasticity is rejected and hence there is homoscedasticity as reported in appendix D. 


\subsection{Variance decomposition}

The estimation of the VAR model in this study has indicated that the lag length determined with the use of Akaike Information Criteria (AIC) is ought to be five. Having established both the lag length and the causality direction the variance decomposition is carried out to find the share of shocks on business confidence. The variance decomposition results are reported in table 3 below.

Table 3: Business confidence Variance Decomposition

\begin{tabular}{cccc}
\hline Period & S.E. & BUSCO & INFL \\
\hline 1 & 7.685010 & 100.0000 & 0.000000 \\
2 & 10.10684 & 98.29077 & 1.709226 \\
3 & 11.95201 & 94.21959 & 5.780415 \\
4 & 13.47841 & 89.18785 & 10.81215 \\
5 & 14.74532 & 84.48374 & 15.51626 \\
6 & 15.76755 & 80.66478 & 19.33522 \\
7 & 16.56748 & 77.78870 & 22.21130 \\
8 & 17.17856 & 75.70812 & 24.29188 \\
9 & 17.63796 & 74.23327 & 25.76673 \\
10 & 17.98026 & 73.19590 & 26.80410 \\
\hline Variance Decomposition of INFL & & & \\
Period & & 3 S.E. & INFL \\
\hline 1 & 1.385471 & 1.613919 & 98.38608 \\
2 & 2.120587 & 1.068149 & 98.93185 \\
3 & 2.507257 & 0.845146 & 99.15485 \\
4 & 2.677645 & 0.745200 & 99.25480 \\
5 & 2.739235 & 0.718013 & 99.28199 \\
6 & 2.756485 & 0.734291 & 99.26571 \\
7 & 2.759860 & 0.770884 & 99.22912 \\
8 & 2.760505 & 0.811780 & 99.18822 \\
9 & 2.761212 & 0.848564 & 99.15144 \\
10 & 2.762152 & 0.878349 & 99.12165 \\
\hline
\end{tabular}

Cholesky Ordering: BUSCO INFL

The business confidence variance decomposition analysis reveals that inflation shock contributes largely to business confidence. Inflation accounted for about $2 \%$ in the first, $6 \%$ in the second period. The variance increases with each period as shown in table 3. In addition to the variance decomposition, the generalised impulse response (GIRF) analysis is done to ascertain the impact of inflation uncertainty on business confidence.

\subsection{Generalised Impulse Response Functions (GIRF) analysis}

The three variable scenario we are have on this study compels us to have present the impulse response function in the form,

$$
Y_{t}=A_{1} Y_{t-1}+\cdots \cdots+A_{p} Y_{t-p}+\amalg_{t}=\Phi(B) U_{t}=\sum_{i=0}^{\infty} \Phi_{i} U_{t-i}
$$

where $\operatorname{cov}\left(U_{t}\right)=\Sigma, \Phi$ is the moving average (MA) coefficients measuring the impulse. Since it is not possible to shock one variable with affecting the other variable, the Cholesky decomposition is preferred, which considers the lower triangular matrix (Q) from the variant B shown below.

$$
B=\left[\begin{array}{lll}
b_{11} & b_{12} & b_{13} \\
0 & b_{22} & b_{23} \\
0 & 0 & b_{33}
\end{array}\right]
$$

We then get $\Sigma=\theta \theta^{\prime}$ such that (4) is written as $Y_{t}=\sum_{i=0}^{\infty} \Theta_{i} w_{t-i}$ 
Where $\Theta=\Phi_{i} \theta, w_{t}=\theta^{-1} U_{t}$. IRF are used to evaluate the effectiveness of a policy changes I an economy. The problems embedded with the impulse response functions (IRF) as opposed to GIRF are that IRF is sensitive to the variables ordering and omitting some important variables leads to some distortions in the IRF and thus yield worthless results. It is at this point that Pesaran and Shin (1998) proposed the GIRF to curb such problems. It should also be noted that the results from the response functions may not be valid if the VAR model is not stable, as such the stability test was performed and the results are shown on figure 1 below.

Figure 1: Inverse roots of AR characteristic polynomial

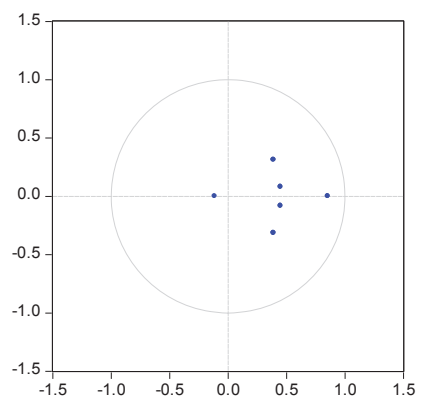

The inverse roots of AR characteristic polynomial reveal the dots lie within the circle, suggesting the existence of stability in the VAR and as such the results obtained from the IRF would be deemed reliable. The stability test does not on its own guarantee that the results from the GIRF will be valid. This, according to Hyeongwoo (2009) will not be consistent and thus poses a challenge especially if the covariance matrix is non-diagonal. The conflict of the GIRFs will trivially apply to the VEC models, hence lead to misleading economic inferences. The results of the covariance matrix are presented in appendix $A$ and such results show that the matrix is indeed diagonal and as a result the GIRF would be consistent.

The general impulse response functions of the variables included in the VAR as shown below are based on the 95\% band and the dashed lines in each graph show the 95\% confidence bands. The impulse response functions are plotted over a 10 - quarter horizon. Theory postulates that inflation uncertainty makes businesses lose confidence and hence a negative relationship. Businesses do lose confidence when there is high inflation as shown in graph of BUSCO to INFL. The solid line falling in period one up to period five and then becomes steady through period seven and then starts increasing slowly till period ten. The GIRF analysis do suggest that an unexpected increase in inflation uncertainty ends to provide a negative jolt to business confidence from period one

Figure 2: Response of Business Confidence to shocks to other variables

Response to Generalized One S.D. Innovations \pm 2 S.E.

Response of BUSCO to BUSCO

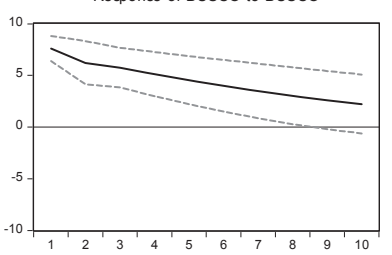

Response of BUSCO to GDPG

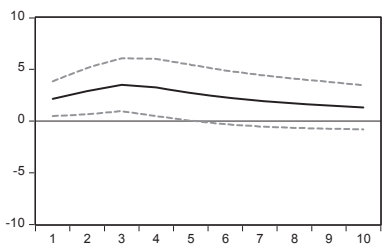

Response of BUSCO to INFL

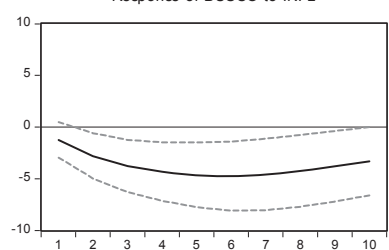

Inflations reacts positively to a shock in business confidence, meaning that when business confidence increases unexpectedly, there will be slide rise in inflation from period one till period two.

\section{Conclusions}

This study empirically tests the effect of inflation shocks on business confidence in South Africa using the quarterly data from 1993 to 2013. With the premise that when inflation easing, the economy seems to gain momentum and boots business confidence. Business owners and/managers would be optimistic about the prospects of their company 
performance. Prior to getting the results, some preliminary diagnostics were performed (causality and unit root tests) and the results from the unit root test showed that both the business confidence and inflation were I(1) while GDPG was I(0). With such properties in the data, it suggested a possibility of long run relationship amongst the variables since two variables were integrated of higher order. Otherwise we could have no long run if two of the variables were integrated of a lower order [i.e. I(0)]. Causality tests on the other hand provide evidence there is unidirectional causation from inflation shock to business confidence shock.

The Cholesky variance decomposition revealed that although inflation account for about 2 percent in the initial stages, it did get the momentum as times went by, with inflation accounting for about 27 percent to shocks in business confidence. Such price uncertainty cannot be ignored when it comes to policy making. The GIRF also confirmed that inflation uncertainty does cause some negative shocks on how business managers/owners perceive the future of their business prospects. The study results do support the negative relationship between business confidence and inflation uncertainty in South Africa as postulated by economic theory.

\section{References}

Bai, J. and Ng, S. (2001). A New Look at Panel Testing of Stationarity and the PPP Hypothesis, BC Working Paper 501, available at http://fmwww.bc.edu/ec-p/wp501.pdf. Accessed 20 September 2013.

Collins, D. (2001). The relationship between business confidence surveys and stock market performance, Investment Analysts Journal, No. 54, 9-17.

Dennis, W.J. (2003). Raising response rates in mail surveys of small business owners: results of an experiment, Journal of Small Business Management, Vol. 41 No. 3, pp. 278-295.

Friesner, D, Khayum, M and McPherson, M. (2006). Interpreting Business Sentiment Surveys: A Factor Analysis Approach, Journal of Business and Public Affairs, Vol. 33 No. 1, pp. 77-96.

Friesner D, Khayum, M. and Schibik, T. (2013). Characteristics of the information content in business sentiment surveys, American Journal of Business, Vol. 28 No. 1, pp. 19-37.

Hansson, J, Jansson, T. and Löf, M. (2005). Business survey data: do they help in forecasting GDP growth?, International Journal of Forecasting, Vol. 21 No.2, pp. 377-389.

Hyeongwoo, K. (2009). Generalised impulse responses Analysis: General or Extreme? Available at http://mpra.ub.unimuenchen.de/17014/. Accessed 20 September 2013.

Kershoff, G. (2000). Measuring business and consumer confidence in South Africa, Available at www.ber.ac.za/Knowledge /pkDownloadDocument.aspx?docid=4128. Accessed 19 September 2013.

Nakamura, L. and Trebing, M. (2008). What does the Philadelphia Fed's Business Outlook Survey say about local activity? Available at: www.philadelphiafed.org/research-and-data/publications/research-rap/2008/business-outlook-survey-local-activity.pdf. Accessed 15 August 2013).

Pellissier, G.M. (2002). Business confidence and the South African business cycle, Journal for the Study of Economics and Econometrics, Vol. 26 No. 2, pp. 51-67.

Pesaran, H.H. and Shin, Y. (1998). Generalised impulse response analysis in linear multivariate model, Economic Letters, Vol.58 No. 1 , pp. 17-29.

Taylor, K.B. and McNabb, R. (2007). Business cycles and the role of confidence: evidence for Europe, Oxford Bulletin of Economics and Statistics, Vol. 69 No.2, pp. 185-208.

Van Rooyen, D. (2011). The U-turn: Business confidence in a Karroo town, Southern African Business Review, Vol. 15 No. 2, pp. $122-$ 142.

\section{Appendices}

Appendix A: Residual Covariance matrix

\begin{tabular}{|c|c|c|c|}
\cline { 2 - 4 } \multicolumn{1}{c|}{} & BUSCO & GDPG & INFL \\
\hline BUSCO & 57.7916 & 4.0291 & -1.6605 \\
\hline GDPG & 4.0291 & 3.4623 & -0.4562 \\
\hline INFL & -1.6605 & -0.4562 & 1.8066 \\
\hline
\end{tabular}

Appendix B: VAR Serial Correlation LM Test results

\begin{tabular}{ccc}
\hline Lags & LM-Stat & Prob \\
\hline 1 & 11.15979 & 0.2649 \\
2 & 10.91274 & 0.2817
\end{tabular}




\begin{tabular}{cll}
3 & 6.594977 & 0.6792 \\
4 & 35.31595 & 0.0001 \\
5 & 9.896466 & 0.3589 \\
6 & 8.066951 & 0.5274 \\
7 & 5.009250 & 0.8335 \\
8 & 7.959646 & 0.5382 \\
9 & 6.360641 & 0.7034 \\
10 & 4.490329 & 0.8763 \\
11 & 3.774751 & 0.9256 \\
12 & 8.555833 & 0.4792 \\
\hline
\end{tabular}

Appendix C: VAR Normality test

Null Hypothesis: residuals are multivariate normal

\begin{tabular}{ccccc}
\hline Component & Skewness & Chi-sq & df & Prob. \\
\hline 1 & 0.328481 & 1.402697 & 1 & 0.2363 \\
2 & -0.107473 & 0.150155 & 1 & 0.6984 \\
3 & -0.277922 & 1.004128 & 1 & 0.3163 \\
\hline Joint & & 2.556980 & 3 & 0.4651 \\
\hline \hline Component & Kurtosis & Chi-sq & df & Prob. \\
\hline 1 & 3.861024 & 2.409429 & 1 & 0.1206 \\
2 & 4.250152 & 5.079357 & 1 & 0.0242 \\
3 & 4.555554 & 7.864182 & 1 & 0.0050 \\
\hline Joint & & 15.35297 & 3 & 0.0015 \\
\hline \hline Component & Jarque-Bera & df & Prob. & \\
\hline 1 & 3.812125 & 2 & 0.1487 & \\
2 & 5.229512 & 2 & 0.0732 & \\
3 & 8.868310 & 2 & 0.0119 & \\
\hline Joint & 17.90995 & 6 & 0.0065 & \\
\hline \hline
\end{tabular}

Appendix D: Heteroskedasticity test - No cross terms

Joint test:

\begin{tabular}{|c|c|c|c|c|c|}
\hline Chi-square $=77.905$ & Prob. $=0.296$ & & & & \\
\hline \multicolumn{3}{|c|}{$\begin{array}{l}\text { Individual components: } \\
\end{array}$} & & & \\
\hline Dependent & R-squared & $F(12,65)$ & Prob. & Chi-sq(12) & Prob. \\
\hline res1*res1 & 0.171400 & 1.120462 & 0.3596 & 13.36917 & 0.3428 \\
\hline res2*res2 & 0.149020 & 0.948542 & 0.5058 & 11.62355 & 0.4764 \\
\hline res3*res3 & 0.115058 & 0.704264 & 0.7416 & 8.974553 & 0.7051 \\
\hline res2*res1 & 0.095559 & 0.572298 & 0.8564 & 7.453584 & 0.8262 \\
\hline res3*res1 & 0.118100 & 0.725376 & 0.7216 & 9.211815 & 0.6847 \\
\hline res3*res2 & 0.220546 & 1.532639 & 0.1353 & 17.20256 & 0.1421 \\
\hline
\end{tabular}

Appendix E: Leverage Plot of Variables

BUSCO vs Variables (Partialled on Regressors)
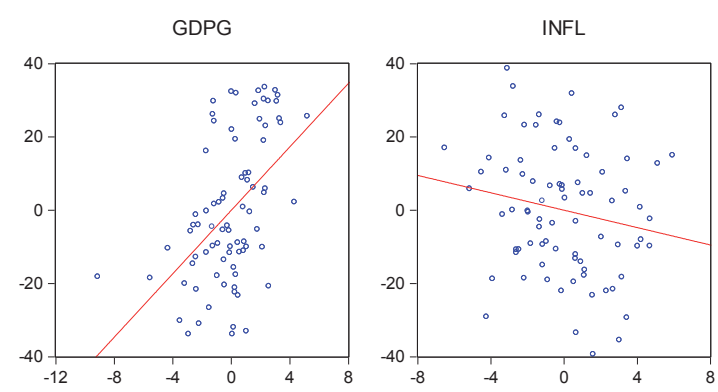